\title{
Fundamentos para o conteúdo e a implementação da pós-graduação em Ecologia
}

\section{Curriculum and implementation guidelines for graduate studies in Ecology}

\section{Bases para el contenido y la implementación del posgrado en Ecología}

Gonçalo Ferraz, doutor em Ecologia e Biologia Evolutiva pela Universidade de Columbia, Estados Unidos. Endereço: PDBFFINPA, Av. André Araújo, 2936. CEP: 69060-000 - Manaus, AM. Telefone: (92) 3644-0536. E-mail: ferrazg@si.edu.

Glauco Machado, doutor em Ecologia pela Universidade Estadual de Campinas. Endereço: Departamento de Ecologia, Instituto de Biociências, Universidade de São Paulo - Rua do Matão, Travessa 14, 321. CEP: 05508-900 - São Paulo, SP. Telefone: (11) 30917488. E-mail: glaucom@ib.usp.br.

Paulo R. Guimarães Jr., doutor em Ecologia pela Universidade Estadual de Campinas. Endereço: Departamento de Ecologia, Instituto de Biociências, Universidade de São Paulo - Rua do Matão, Travessa 14, n 321. CEP: 05508-900 - São Paulo, SP. Telefone: (11) 3091-7597.E-mail: prguima@ib.usp.br.

Samantha Koehler, doutora em Biologia Vegetal pela Universidade Estadual de Campinas. Endereço: Departamento de Ciências Biológicas - Rua Artur Riedel, 275. CEP: 09972-270 - Diadema, SP. Telefone: (11) 3319-3300. E-mail: samantha.koehler@gmail. com. 


\section{Resumo}

A recente expansão do investimento brasileiro na pósgraduação em Ecologia cria uma oportunidade de progresso nos programas de treinamento. Não há progresso sem metas, e as metas de um esforço conjunto se beneficiam da partilha de valores fundamentais. Este artigo contribui para o debate em curso, propondo um conjunto de áreas de conhecimento fundamentais para a formação do ecólogo. A Matemática, a Estatística e a Evolução são apresentadas como 'pilares'; a História Natural, a Lógica e a Retórica são vistas como o 'cimento' que dá consistência ao treinamento. Finalmente, sem deixar de frisar a importância da criatividade local, propomos um conjunto de princípios gerais de implementação para transformar os valores fundamentais em uma realidade de treinamento inovadora e produtiva.

Palavras-chave: Currículo. Ecologia. Pós-Graduação. Matemática. Estatística. Evolução. História Natural. Lógica.

\section{Abstract}

The recent expansion of Brazilian investment in graduate ecology training creates a special opportunity for progress. Progress requires goals, and the goals of a joint effort should be built upon shared principles. This article contributes to the ongoing debate about graduate-level training in ecology by proposing a set of disciplines that offer a fundamental background for the professional ecologist. Mathematics, Statistics, and Evolution are presented as supporting 'pillars', whereas Natural History, Logic, and Rhetoric are viewed as binding disciplines that give consistency to a training program. To conclude, we offer general principles of implementation aimed at transforming the proposed values into an innovative and productive training reality.

Keywords: Curriculum. Ecology. Graduate Training. Mathematics. Statistics. Evolution. Natural History. Logic. 


\section{Resumen}

La reciente expansión de la inversión brasileña en el posgrado en Ecología ha creado una oportunidad única de progreso. No hay progreso sin metas y las metas de un esfuerzo compartido se benefician cuando se comparten valores fundamentales. Este artículo contribuye al debate en curso sobre el posgrado en Ecología proponiendo un conjunto de áreas de conocimiento esenciales para la formación en esta área. Matemática, la estadística y la evolución se presentan como 'pilares'; la historia natural, la lógica y la retórica son disciplinas que dan consistencia al programa de formación. Por último, al tiempo que destaca la importancia de la creatividad local, se propone una serie de principios generales de implementación para transformar los valores centrales en una realidad innovadora y productiva.

Palabras clave: Currículo. Ecología. Posgrado. Matemática. Estadística. Evolución. Historia Natural. Lógica.

\section{Introdução}

Com mais de 40 programas de pós-graduação em Ecologia, o investimento brasileiro no treinamento de ecólogos mais do que duplicou nos últimos seis anos (SCARANO, 2008). Hoje, o País ocupa uma posição de liderança inequívoca na América Latina e de crescente visibilidade no mundo. Seguindo o exemplo de Martins et al. (2007), propomos uma reflexão sobre o rumo a seguir. Adotaremos o mesmo enfoque prático de Rocha et al. (2008), no entanto, em vez de centrar nossas observações em um programa particular, daremos prioridade à formulação de fundamentos gerais para a construção de um programa de pós-graduação em Ecologia. Nossa proposta assenta sobre uma única premissa: o objetivo de um programa é a capacitação de profissionais para formular e responder a perguntas sobre distribuição e abundância de organismos no espaço e no tempo. Esse objetivo é declarado no seu sentido mais amplo, incluindo uma vasta gama de tópicos que tradicionalmente caem no âmbito da Ecologia, desde a evolução do comportamento até a variação geográfica da riqueza 
de espécies. A medida de sucesso do programa é a sua contribuição para o progresso intelectual da disciplina e para a resolução de problemas ecológicos relevantes para a sociedade. Pretende-se que os profissionais formados sejam reconhecidos pela inteligibilidade do seu trabalho e pela sua capacidade não só de responder a perguntas, mas principalmente de identificar as perguntas de maior repercussão para o avanço do conhecimento.

Os fundamentos que vamos apresentar se referem ao conteúdo e à implementação do programa. Não sugerimos disciplinas concretas, mas pretendemos inspirar a tomada de decisões sobre a grade, o tipo de disciplinas e suas ementas. Dividiremos o texto sobre conteúdo em duas partes que representam, metaforicamente, os pilares e o cimento da construção do programa. Os pilares sãoáreas de conhecimento sobre as quais se apoia a Ecologia e que podem ser tratadas individualmente durante o treinamento. O cimento diz respeito a áreas que, embora possam ter um tratamento individualizado fora do programa, dentro dele serão tratadas como aspectos subjacentes à atividade de qualquer profissional, permeando todo o treinamento. Os pilares são a Matemática, a Estatística e a Evolução. O cimento é uma mistura de História Natural, Lógica e Retórica. Finalmente, frisando que há muitas formas diferentes e igualmente viáveis de organizar um programa de pós-graduação, encerramos o documento com a formulação de alguns cuidados gerais para a implementação do conteúdo proposto.

A metáfora da construção ajuda a distinguir o que deve vir de dentro e o que deve vir de fora do programa. Em algum estágio simplificado do planejamento de uma obra, o suporte estrutural depende de quantos e quais tipos de pilares são incluídos no desenho. A execução da obra, no entanto, depende de um cimento que não necessariamente afeta as decisões estruturais e que pode ser visto como um componente fundamental, mas externo. A dicotomia entre 'pilares' e 'cimento' oferece duas vantagens: a primeira é separar os tópicos prioritários para inclusão em disciplinas (pilares) dos tópicos que não têm de ou não podem ser abordados em detalhe na sala de aula (cimento); a segunda é ajudar a identificar os atributos-chave de um bom candidato. Dada a importância do cimento e a prioridade 
ao tratamento dos pilares nas disciplinas, é desejável que os alunos ingressem no programa bem 'cimentados', isto é, com aptidões amadurecidas naquelas atividades que são fundamentais, mas que não são necessariamente tratadas com profundidade ou regularidade nas disciplinas.

Pode causar estranhamento que a palavra 'Ecologia' não apareça em destaque nem nos pilares nem no cimento. Ressaltamos que essa omissão não é um descuido, mas sim um cuidado que reflete a nossa convicção de que a Ecologia deve ser entendida como o produto final da obra metafórica que é o programa de treinamento. Não há dúvida de que a Ecologia possui um corpo próprio de conhecimento e teoria (TURCHIN, 2001; HUBBELL, 2001; LEVIN et al., 2009), mas o foco principal deste artigo é a diversidade das contribuições de várias áreas do conhecimento e sua importância para a formação de ecólogos. Os limites exatos do que se entende por conhecimento ecológico não têm necessariamente de ser estabelecidos pelo programa. Idealmente, esses limites poderão variar livremente de programa para programa ou mesmo entre estudantes de um mesmo programa. Dessa forma, o enfoque na integração de várias áreas de conhecimento evita a imposição de limites externos à Ecologia e fomenta um treinamento que tira máximo partido da atual multiplicidade de perspectivas na disciplina. Em vez de encarar a multiplicidade como desordem e tentar delimitá-la, o treinamento deve encarar a multiplicidade como um sinal saudável de vitalidade intelectual e identificar as principais forças que movem essa vitalidade.

Se existem benefícios em permitir uma fluidez saudável nos limites da disciplina, também existem vantagens em não compartimentalizar excessivamente o seu interior. Nesse ponto, surge talvez a inovação mais importante do nosso texto. Reconhecemos a utilidade dos compartimentos amplamente estabelecidos como 'ecologia terrestre','ecologia aquática', 'ecologia de populações', 'ecologia de comunidades' ou 'ecologia de ecossistemas'; no entanto, propomos um treinamento de pós-graduação que enfatiza uma visão transversal e integradora dos compartimentos. Essa proposta convida o aluno a olhar para além das áreas de especialização dentro da Ecologia e 
estudar em profundidade como diferentes linhas de pensamento (que transcendem a Ecologia) se complementam, contribuem para e condicionam o crescimento atual da disciplina. O conteúdo dos três 'pilares' de Matemática, Estatística e Evolução ilustra como é possível integrar a disciplina com outras áreas de conhecimento abordando ao mesmo tempo uma vasta gama de ideias fundamentais dos diferentes compartimentos. A integração será muito mais eficaz se o currículo de graduação incluir uma boa base dos três pilares. Porém nossa proposta vai além de fornecer bases em Matemática, Estatística e Evolução; a proposta é que, ao chegar à pós-graduação, o profissional seja convidado a revisitar a Ecologia de forma transversal, mas em profundidade, por meio de grandes prismas interdisciplinares.

Este texto não será a última palavra sobre o tema do treinamento transversal. Pode haver outros pilares, e a listagem de tópicos pode ser amplamente alterada. Os tópicos listados abaixo para cada um dos pilares devem ser vistos como uma lista de sugestões particularmente férteis e não como um catálogo exaustivo de tudo o que um aluno tem de saber ao sair do programa. Para além disso, importa ressaltar que uma visão transversal não equivale a eliminar qualquer vestígio de compartimentos no treinamento. Uma disciplina de Matemática aplicada à Ecologia, por exemplo, pode ser estruturada por níveis de organização biológica, ou, ainda, uma disciplina de Ecologia de comunidades pode dar particular atenção ao papel da abstração matemática sem sequer incluir a palavra 'matemática' no seu título. Como um teste à nossa proposta de fundamentos, convidamos o leitor a procurar ideias relevantes para a sua área de especialização nos tópicos listados para cada pilar. Nosso texto terá utilidade na medida em que o leitor reconhecer a possibilidade de integrar compartimentos da Ecologia e estabelecer relações com os 'pilares' de conhecimento, sem perder a riqueza e diversidade de conteúdo que definem a própria Ecologia.

\section{Conteúdo - pilares}

A Ecologia estuda fenômenos biológicos e sua interação com o meio ambiente, seja por meio de raciocínios abstratos ou 
de observação. Sendo a Matemática a principal ferramenta de organização do raciocínio abstrato nas ciências naturais, ela aparece naturalmente como o primeiro pilar. Quando a compreensão dos fenômenos biológicos envolve a análise de observações, é fundamental saber o quanto essas observações representam apropriadamente o fenômeno que se pretende explicar. A Estatística, que é o segundo pilar, oferece um referencial para organizar observações, apoiar a inferência e quantificar a incerteza associada aos resultados de análise. Finalmente, "nada em biologia faz sentido exceto à luz da evolução" (DOBZHANSKY, 1973), e a Ecologia não escapa a essa afirmação. As aplicações de Matemática e Estatística contribuem eficazmente para a compreensão dos fenômenos biológicos quando enraizadas em uma visão de como esses fenômenos apareceram na natureza - essa visão requer uma compreensão profunda da Evolução.

\section{Pilar I: A Matemática como apoio à abstração e à generalização}

Se pensarmos o quanto a Ecologia é uma disciplina jovem, com um corpo de teoria diversificado e limites difusos, fica claro como a Matemática pode influenciar a escolha dos problemas de trabalho e o seu tratamento. Nesse contexto, é importante incutir nos alunos um conhecimento básico de algumas ferramentas matemáticas concomitantemente com o estudo de problemas ecológicos gerais, estabelecendo uma perspectiva histórica da disciplina e um apoio para entender a literatura atual. Os tópicos abaixo exemplificam como diferentes ferramentas matemáticas contribuem para a compreensão de processos ecológicos. Longe de apresentar uma lista exaustiva de tópicos, resumimos apenas algumas possibilidades de aplicação do conhecimento matemático em temas que nos parecem particularmente abrangentes e atuais. Ao listar os tópicos abaixo, não propomos que todos eles sejam necessariamente incluídos em grades curriculares da pós-graduação em Ecologia. Pensamos, sim, que a matemática aplicada deve ter uma presença forte no treinamento de pós-graduação. A capacidade de aplicação ao nível da pós-graduação, no entanto, será proporcional ao treinamento matemático básico recebido na graduação. Por isso, propomos que a compreensão em profundidade e a familiaridade com a aplicação da Matemática 
ocupem um lugar central no treinamento, mas alicerçadas em um embasamento que, sempre que possível, deveria vir da graduação.

1. Como as equações diferenciais apoiam a compreensão da dinâmica populacional. Quase toda a teoria de dinâmica populacional deriva de uma equação diferencial que expressa o crescimento exponencial em tempo contínuo (GOTELLI, 2007). Muitos modelos de densodependência, competição, predação e comunidade são variações sobre o tema do crescimento exponencial. A equação logística e os modelos Lotka-Volterra ainda ocupam um lugar central na teoria ecológica e sua compreensão requer uma familiaridade mínima com cálculo e equações diferenciais;

2. Como a álgebra linear ajuda a representação do crescimento de populações estruturadas. Tipicamente, os modelos de crescimento populacional com equações diferenciais supõem que todos os indivíduos da população são iguais. Quando se pretende explorar a variação intrapopulacional nos parâmetros de sobrevivência e fertilidade, a aplicação de álgebra linear permite subdividir a população em grupos com parâmetros diferentes e contribuições distintas para o destino da população (CASWELL, 2001). Os modelos estruturados têm muita flexibilidade, importantes aplicações de manejo e um enorme potencial de desenvolvimento teórico (ELLNER; REES, 2006);

3. Como a topologia apoia o estudo de interações e outros processos ecológicos. O livro Food Webs and Niche Space de Joel E. Cohen (1978) exemplifica uma das primeiras aplicações de um ramo da topologia, a teoria de grafos, ao estudo de redes tróficas. Três décadas depois, é possível encontrar aplicações de topologia desde o estudo de interações ecológicas até à biogeografia histórica e à dinâmica de metapopulações, passando pelo estudo de sistemas de acasalamento, interações sociais e epidemiologia. Essas aplicações se centram na teoria de grafos, mas também incluem o uso de topologia algébrica no estudo de transformações não lineares em sistemas ecológicos (PRAGER; REINERS, 2009);

4. Como a teoria de jogos explica a evolução do comportamento animal. John Maynard Smith, no livro Evolutionary Theory of Games (1982), aplicou na Biologia uma ferramenta matemática desenvolvida para o estudo de interações econômicas e políticas em 
que vários 'jogadores' procuram definir estratégias que maximizem seu êxito na interação. Em Biologia, as estratégias podem ser transmitidas hereditariamente, e o êxito consiste em maximizar a quantidade de descendentes. É interessante que os alunos ganhem familiaridade com a teoria de jogos como ferramenta de estudo de interações biológicas e que compreendam o conceito de estratégia evolutivamente estável; e

5. Como as equações diferenciais de difusão e de passeios aleatórios apoiama representação do movimento de organismos. Os processos de difusão detalhadamente estudados na Física têm aplicações no estudo de difusão de nutrientes e movimento de organismos marinhos (OKUBO, 1980). Mais recentemente, a combinação do conhecimento sobre difusão com os modelos de passeio aleatório tem contribuído para a compreensão do movimento de organismos não só em ambientes aquáticos, mas também terrestres (BÖRGER; DALZIEL; FRYXELL, 2008). O progresso nas técnicas de coleta de dados sobre movimento anuncia ainda mais progresso analítico em um futuro próximo.

\section{Pilar II: A Estatística como apoio à analise de dados}

Qualquer abstração pede uma confirmação empírica. Uma hipótese explicativa de um fenômeno na natureza leva naturalmente a uma previsão de como o fenômeno se desenrola na realidade. $A$ hipótese tem aplicabilidade se a sua previsão for testável. É claro que o trabalho teórico de abstração e o trabalho empírico de análise de dados são atividades inseparáveis. No entanto, a confrontação com os dados - que são sempre uma representação incompleta da realidade - obriga a considerações sobre incerteza. Essas considerações raramente aparecem na abstração matemática, mas elas são um dos elementos fundamentais do teste de hipóteses e estimativa de parâmetros. Para lidar melhor com a incerteza, o biólogo precisa estudar Estatística. Em seguida, listamos alguns tópicos de Estatística particularmente úteis para o profissional de Ecologia.

1. Noções básicas de probabilidade e distribuições de probabilidade. A familiaridade com regras básicas de probabilidade permite olhar um conjunto de dados e responder a perguntas como: de que forma 
esses dados podem ter resultado da realidade biológica que eu estou estudando? Por exemplo, se o processo em estudo resulta da junção de um evento de distribuição Poisson (e.g., abundância de organismos) com um evento binomial (e.g., sucesso de captura), que distribuição de probabilidade eu espero encontrar nos meus dados? A explicação formal de como os dados resultam de um processo hipotético requer um conhecimento sobre distribuições de probabilidade (ROSS, 2007);

2. Desenho experimental. A forma mais eficaz de testar uma hipótese ainda é a experimentação controlada (PLAT, 1964). Apesar de essa ideia ter sido proposta há muito tempo por Ronald A. Fisher no livro The Design of Experiments (1935), a maioria dos alunos desconhece os princípios básicos de um bom desenho experimental, que incluem comparação com um grupo controle, aleatorização das amostras para cada grupo experimental e replicação do experimento. Além de permitir testar hipóteses de forma rigorosa, um bom desenho experimental permite que os resultados sejam analisados de forma simples, usando técnicas de análise frequentista especialmente desenvolvidas para essa finalidade;

3. O modelo como hipótese, teste de hipóteses e seleção de modelos. O processo de amostragem e análise conhecido por 'modelagem' é um exercício extraordinariamente abrangente de representação simplificada da realidade. Esse exercício permite descobrir verdades sobre um objeto de estudo, mas ele não pretende atingir e jamais atingirá uma representação correta do objeto. Isso é assim porque a qualidade da representação depende daquilo que se pretende descobrir sobre o objeto e não do objeto em si. O aluno precisa entender os fundamentos do teste de hipóteses (GOTELLI; ELLISON, 2011) e, concebendo o modelo como uma hipótese, ganhar familiaridade com critérios de escolha de modelos (BURNHAM; ANDERSON, 2002);

4. Verossimilhança. $\dot{E}$ indispensável que os alunos entendam em profundidade o papel da verossimilhança na estimativa de parâmetros e na seleção de modelos. O conjunto de procedimentos e opções teóricas que levam o pesquisador a perguntar 'qual a combinação de valores de parâmetros que maximizam a probabilidade de ver o que eu vi?' tem uma abrangência sem par em 
múltiplas áreas da ciência e posturas teóricas de análise de dados (HILBORN; MANGEL, 1997);

5. Bayes e modelos lineares hierárquicos. A abrangência da verossimilhança se estende à análise de dados bayesiana (ROYLE; DORAZIO, 2008), que opera sobre princípios teóricos próprios e, em alguns pontos, contrastantes com os da Estatística correntemente ensinada nas graduações de Biologia. Os alunos precisam saber se localizar entre diferentes opções teóricas de análise e, acima de tudo, desenvolver uma postura pluralista e pragmática face à opção entre tipos de análise. A análise bayesiana é particularmente útil no estudo de modelos lineares hierárquicos que distinguem formalmente o processo biológico subjacente aos dados do processo amostral de coleta;

6. Técnicas modernas de estimativa de parâmetros. Há 50 anos, o conhecimento teórico já permitia distinguir, por exemplo, entre análises frequentistas e bayesianas, mas os meios de computação eram insuficientes para executar a maior parte das análises bayesianas. Essa limitação desapareceu com a disponibilidade de computadores e com a introdução de um algoritmo numérico em particular, o Markov Chain Monte-Carlo (MCMC). É importante que os alunos entendam como os avanços computacionais abriram opções de análise e que compreendam a aplicação de técnicas como o MCMC (KÉRY, 2010);

7. Programação. A flexibilidade e autonomia na análise de dados requerem familiaridade com uma linguagem de programação. Muitas soluções de análise aparecem como rotinas clicáveis em pacotes de Estatística, mas o uso das análises como 'caixas pretas' limita a sua compreensão e barra a busca de soluções inovadoras. Existem várias linguagens de alto nível que podem servir bem às necessidades de qualquer aluno de pós-graduação em Ecologia entre elas MATLAB, Mathematica, Octave e R. Dentre as várias opções, o R tem o atrativo de ter atualmente um grande número de utilizadores e por isso dar uma grande facilidade de acesso à ajuda online (BOLKER, 2008); e

8. Tomada de decisões estruturada. Muitos estudos ecológicos são motivados por preocupações ambientais. O programa deveria educar essa motivação, clarificando a conexão entre a Estatística 
e o processo de tomada de decisões de manejo. Essa conexão é abordada pela disciplina de tomada de decisões estruturada (CLEMEN; REILLY, 2004) e pelo manejo adaptativo (WALTERS, 2001), ambas amplamente utilizadas no gerenciamento de ecossistemas aquáticos e recursos hídricos, mas altamente pertinentes em outros contextos. Operacionalmente, os alunos precisam aprender a incorporar a incerteza associada ao resultado de uma decisão de manejo no exercício de modelagem de processos ecológicos. Essa é uma das áreas de trabalho mais férteis na contribuição da Ecologia para a sociedade.

\section{Pilar III: A Evolução como perspectiva histórica}

É comum falar-se de tempo ecológico em oposição a tempo evolutivo, como um tempo suficientemente curto para que uma população permaneça em um estado estável (HAIRSTON et al., 2005). Essa estabilidade é vista como um resultado das características atuais da população e do seu ambiente, o que, no extremo, colocaria os fenômenos ecológicos para além da influência da história. Correta ou não, a dicotomia entre tempo ecológico e tempo evolutivo contribui para delimitar o âmbito da Ecologia e coloca a Evolução no centro dessa delimitação. Dessa forma, a Evolução importa não só para dar sentido histórico às observações ecológicas, mas também para entender o que se considera tradicionalmente o limite da disciplina. Dentre os possiveis temas de estudo em Evolução, destacamos os tópicos listados abaixo:

1. Genética de populações. 0 estudo dos mecanismos mendelianos de variação da frequência de alelos de um gene em uma população é fundamental para a compreensão dos processos evolutivos. Além de serem um fundamento, os modelos básicos de genética de populações, como o equilíbrio de Hardy-Weinberg e o modelo Wright-Fisher de deriva genética(HARTL;CLARK,2010), estabelecem um paralelo educativo com a demografia. Como Hardy-Weinberg para a genética de populações, o crescimento exponencial oferece um modelo nulo para a demografia. Em ambos os casos, o conhecimento avança por um exercício gradual de levantamento das premissas de um modelo exageradamente simples, mas muito geral; 
2. Genética quantitativa. Enquanto a perspectiva mendeliana pressupõe a identificação de um gene, grande parte da biologia evolutiva deriva da observação da variação fenotípica de caracteres quantitativos, independentemente desses caracteres terem ou não uma base genética conhecida. A genética quantitativa muda o foco das proporções mendelianas para o fenótipo, estudando as contribuições da variação genética e da variação ambiental para a variação fenotípica observada. Os alunos precisam reconhecer a continuidade conceitual e a complementaridade das perspectivas mendeliana e quantitativa, assim como o alcance da interação entre genótipo, fenótipo e ambiente (LEWONTIN, 2002);

3. Condições para a atuação da seleção natural. É fundamental que os profissionais de Ecologia entendam que a eficácia da seleção natural como agente de mudança evolutiva dependerá das bases genéticas da variação fenotípica. A mudança causada pela seleção natural é proporcional à herdabilidade do caráter em causa, que, por sua vez, corresponde à divisão da variância genética aditiva pela variância fenotípica (FUTUYMA, 1998). Essas ideias de genética quantitativa formam um referencial indispensável para entender controvérsias em torno do programa adaptacionista e enfatizam como restrições filogenéticas e pleiotropia, entre outros fatores, impõem limites à otimização de atributos fenotípicos;

4. Importância relativa de processos genéticos e demográficos no destino das populações. A noção popular de que a 'biodiversidade' abrangendo variabilidade de ecossistemas, de espécies e de genes é algo intrinsecamente positivo pode induzir à convicção irrefletida de que qualquer redução de variabilidade genética aumenta a probabilidade de extinção de uma população. Um ecólogo precisa ir além da superfície desse tópico, compreendendo diferentes medidas de variabilidade genética e a importância relativa dos mecanismos genéticos e demográficos para o manejo de pequenas populações (LANDE, 1988);

5. Como os eventos históricos e os processos regionais contribuem para a riqueza local de espécies. A maior parte da teoria em ecologia de populações trata de processos locais de relação entre uma população e seu ambiente, cultivando a expectativa de que os processos ecológicos relevantes são relativamente rápidos e 
atuam em escala local. Essa perspectiva, no entanto, é insuficiente para explicar a riqueza local e a variação geográfica da riqueza de espécies (RICKLEFS, 2004). A análise espacial de processos microevolutivos, o estudo de processos ecológicos na especiação e a filogeografia complementam a perspectiva clássica da Ecologia com uma visão evolutiva histórica e regional;

6. Filogenia. O estudo das relações de ancestralidade entre organismos tem repercussões tão abrangentes em Biologia que merece atenção por si só. Os alunos precisam conhecer os principais métodos de inferência de filogenias, em conexão explícita com o treinamento estatístico. Na aplicação à Ecologia, merecem particular atenção o estudo filogenético de interações entre espécies e o uso do método comparativo para inferir relações entre caracteres. No contexto da análise de filogenias moleculares, a abordagem a esse tópico deveria ser suficientemente profunda para permitir uma compreensão da filogenia de espécies como uma rede difusa de histórias evolutivas de genes (MADDISON, 1997). Na atualidade, a construção de filogenias se assenta em grande parte sobre informação molecular, porém os marcadores moleculares e a evolução molecular têm muitas outras aplicações em Ecologia, como resumimos no próximo ponto; e

7. Marcadores moleculares, evolução molecular e suas aplicações. Tal como o poder computacional na Matemática e Estatística, os marcadores moleculares ampliaram os horizontes do factível, possibilitando o tratamento de perguntas anteriormente inacessiveis (AVISE, 2004). Para além da filogenia e filogeografia, o uso de ferramentas moleculares está bastante consolidado na inferência de paternidade e na medição do fluxo gênico entre populações. Em franco desenvolvimento, destaca-se o uso de marcadores para estimar parâmetros demográficos, a identificação de assinaturas de seleção natural, a genômica e o estudo da estrutura filogenética de comunidades. O domínio dessas aplicações requer um conhecimento aprofundado de evolução molecular e, na maior parte dos casos, uma boa compreensão dos modelos de coalescência (WAKELEY, 2008). 


\section{Conteúdo - cimento}

Ninguém espera que a grade curricular do ensino médio inclua alfabetização, mas a maioria de nós reconhece que o ensino médio é inacessível para um analfabeto. Isso não exclui que um aluno ingresse no ensino médio com dificuldades de leitura, ultrapassando essas dificuldades sem ter de cursar uma disciplina de 'alfabetização funcional'. Na pós-graduação, há aptidões comparáveis à alfabetização: assuntos que nem sempre se podem ensinar em uma disciplina, mas que têm de ser cultivados. Quais são essas aptidões para a Ecologia? A primeira é algum nivel de experiência de observação e análise de organismos vivos - uma prática que normalmente recebe o nome de 'História Natural'. A segunda é a prática de articular ideias e avaliar a validade dessas articulações, ou seja, o raciocínio lógico. A terceira aptidão é a Retórica, isto é, a capacidade de comunicar ideias eficazmente de forma verbal ou por escrito.

\section{História Natural}

A Origem das Espécies de Charles Darwin (1859) é um dos melhores documentos da importância da História Natural. Esse livro, que marca profundamente a atividade intelectual de todos os biólogos, não tem Matemática nem Estatística, mas é impregnado de História Natural em cada página. Veja, por exemplo, a discussão sobre a possível história evolutiva da construção de favos por abelhas no capítulo sete: Darwin revisa a história natural de diferentes espécies de abelhas em busca de formas de favos que ajudem a apoiar ou refutar distintas hipóteses evolutivas. Essa revisão, como muitas outras ao longo do livro, não seria possível sem uma profunda experiência de observação e comparação, amparada pela mais genuína curiosidade. O conhecimento de História Natural diversificado e guiado por hipóteses deveria ser como o ar que o biólogo respira. Esse conhecimento, partilhado por muitos biólogos, deve ser motivado inclusive em pesquisadores de outras áreas que queiram se aprofundar em Ecologia. No entanto, apesar de reconhecermos a importância da história natural, não temos um programa pedagógico para incutir no aluno esse tipo de conhecimento. Com ou sem margem para melhoramentos didáticos, é importante 
lembrar que o conhecimento de História Natural é principalmente movido pela curiosidade. Em alguns casos raros, a curiosidade pode ser transmitida pelo exemplo, mas ela é, acima de tudo, algo que tem de vir do aluno.

\section{Lógica}

O avanço de qualquer disciplina científica depende de uma combinação entre a criatividade e a lógica. A criatividade gera ideias, a lógica avalia a sua validade. Uma das formas de estimular o raciocínio lógico em um profissional de Ecologia é prover a ele um treinamento básico de Matemática. Nesse sentido, o programa ganharia em selecionar alunos que não têm receio de Matemática. Além da base matemática, o aluno precisa desfrutar o processo de avaliação de ideias científicas sem medo de discordar de colegas ou professores. 0 respeito não pode ser confundido com submissão nem conformismo; a confrontação de ideias tem de ser praticada como um jogo, em que a vivacidade substitui a animosidade, e a exclusão de uma ideia não significa a exclusão de um jogador. Isso exige uma capacidade de discórdia inquisitiva e um acolhimento positivo da palavra 'crítica'. Tal como a curiosidade, o raciocínio lógico dificilmente cabe no programa de uma disciplina, mas ele deve ser ativamente procurado nos candidatos e cultivado no programa. O que é absolutamente vital é que o jogo de confrontação de ideias se mantenha vivo e intenso dentro do próprio programa. Do contrário, as ideias da casa não sobreviverão fora das fronteiras políticas da academia local.

\section{Retórica}

A sobrevivência das ideias depende não só da sua validade, mas da sua comunicação. A Retórica - arte de comunicar ideias de forma persuasiva e eficaz - é importante no meio científico, principalmente do ponto de vista da eficácia da comunicação, já que a persuasão deveria depender da coerência lógica. É possível discutir aspectos relevantes dessa arte de comunicar em uma disciplina, mas não é desejável entregar aos alunos uma receita fechada de como comunicar. Tal como a História Natural e a Lógica, a Retórica pertence 
ao grupo de aptidões que deveriam ser ativamente procuradas nos candidatos e continuamente cultivadas por meio de todas as atividades do programa. Esse cultivo da comunicação eficaz deve se manifestar por meio de uma variedade de canais de comunicação: desde o e-mail à palestra, passando pelo texto impresso e pela aula. A clareza é uma obrigação profissional.

\section{Implementação}

As sugestões de conteúdo que acabamos de apresentar podem ser postas em prática de muitas formas diferentes, dependendo da realidade institucional e humana do programa. No entanto, existem alguns princípios de ordem prática com aplicabilidade geral. Encerramos este documento com a apresentação de quatro princípios práticos para a implementação dos fundamentos propostos.

\section{Comunicação é tudo}

Pesquisa científica sem comunicação é tão relevante quanto o jornalismo em uma ilha deserta. Para que o programa funcione é essencial que professores e alunos tenham amplas oportunidades de comunicação nos planos bibliográfico, eletrônico e verbal. O recurso bibliográfico essencial é uma biblioteca bem equipada. Com a atual disponibilidade de informação online, existe a tentação administrativa de ignorar a importância da biblioteca como espaço de concentração, de encontro entre pessoas e de consulta livre de uma grande variedade de fontes. A importância desse espaço não morreu com o advento da comunicação eletrônica - pelo contrário, ela pode ser reforçada. No plano da comunicação eletrônica, é importante lembrar que, por diversos motivos, a funcionalidade do acesso à internet ainda não satisfaz as expectativas dos usuários em uma parte das instituições acadêmicas brasileiras. Esse é um ponto que precisa de atenção constante dos programas de pós-graduação, porque, quanto mais universal se torna a comunicação eletrônica, mais limitante é a falta dela. Finalmente, no plano verbal, é construtivo ter um seminário semanal com um palestrante convidado, mantendo um fluxo contínuo de pesquisadores 
visitantes ao programa. Complementando as oportunidades mais formais - como o seminário-, devem-se cultivar amplas oportunidades de interação informal. Isso pode acontecer durante um happy hour após o seminário, mas também em ocasiões menos planejadas, desde que o programa disponha de um espaço físico que favoreça esse tipo de interação.

\section{Flexibilidade sobre raiz coesa}

Os tópicos de conteúdo que apresentamos podem aparecer em uma grade de disciplinas. Há múltiplas maneiras de organizar uma grade, mas importa considerar qual vai ser o lugar da flexibilidade e o lugar da coesão nessa organização. Se um conjunto de professores consegue chegar a acordo sobre quais são os conhecimentos fundamentais que qualquer profissional de Ecologia deve dominar, então esses conhecimentos devem ser transmitidos em um conjunto de disciplinas de tronco comum. Seria naturalmente desejável que todos os alunos do programa cursassem essas disciplinas o mais cedo possivel, após o ingresso. Sobre essa base coesa viria um conjunto de disciplinas de conteúdo mais flexível que os alunos cursariam optativamente, de acordo com a orientação dos seus projetos de pesquisa. Por exemplo, o programa poderia ter três disciplinas de tronco comum incidindo sobre Ecologia, Estatística e Evolução. Essas disciplinas seriam complementadas por uma grade de optativas sobre genética, sistemática, história natural, programação e muitos outros tópicos, refletindo as aptidões dos professores da instituição.

\section{Professores de casa, alunos do mundo}

O programa precisa tirar o máximo partido possivel dos recursos humanos da instituição - daí o princípio 'professores de casa', entendido como um esforço de potencializar o conhecimento local e não como uma recusa ao envolvimento ocasional de professores externos na grade curricular. A 'casa' pode ser a própria instituição do programa, mas também pode ser a cidade, desde que o professor 'de casa' seja alguém a quem o aluno pode aceder com frequência e espontaneidade. Para o bem do programa, no entanto, é desejável que os alunos não sejam só 
'de casa'. O potencial de um candidato à pós-graduação não é facilmente determinado pela instituição de origem, pela geografia ou pelo ambiente socioeconômico. Nessas circunstâncias, a estratégia de recrutar alunos de pós-graduação entre os graduandos da própria instituição é lamentavelmente subótima. A realidade das instituições de ensino, o poder demográfico e a diversidade humana do Brasil só reforçam a importância de captar alunos de qualquer lugar do País ou do mundo.

\section{Metas operacionais}

Nossas recomendações são intencionalmente amplas, porque pretendemos formular fundamentos cuja implementação deve variar de instituição para instituição. É crucial, no entanto, que em cada instituição exista uma consciência clara do que se pretende atingir com o programa a cada momento. Para tal, importa definir metas operacionais claras, incorporadas em um sistema de autoavaliação contínua do programa. Apesar do prefixo 'auto', ressaltamos que, em alguns casos específicos, a avaliação pode e deve ser realizada por agentes externos ao programa. Essa autoavaliação não visa substituir a avaliação da Capes. Enquanto a Capes provê uma avaliação comparada de todos os programas de pós-graduação brasileiros, a autoavaliação oferece um retorno sobre o resultado de ações pontuais implementadas localmente e está livre para respeitar as idiossincrasias de cada programa. Por exemplo, se existe um empenho forte em diversificar o corpo discente, o programa pode definir a meta operacional de captar um mínimo de 50\% de alunos entre candidatos de outras instituições durante os próximos $x$ anos. Para atingir essa meta, podem ser implementadas ações de ajuste ao processo de seleção e de alocação de bolsas que permitam financiar alunos de fora do estado, sempre dentro dos limites dos diplomas legais vigentes. Caso a meta não seja atingida no tempo pretendido, as ações podem ser revisadas. A importância dessas metas não pode ser subestimada. Elas fornecem simultaneamente um rumo para a ação e uma autoavaliação do progresso obtido, que permite corrigir ações futuras. Só assim será possivel transformar os valores fundamentais aqui propostos em uma realidade consequente. 


\section{Referências bibliográficas}

AVISE, J. C. Molecular markers, natural history, and evolution. 2 ed. Sunderland: Sinauer, 2004.

BOLKER, B. M. Ecological models and data in R. Princeton: Princeton University Press, 2008.

BÖRGER, L.; DALZIEL, B. D.; FRYXELL J. M. Are there general mechanisms of animal home range behaviours? A review and prospects for future research. Ecology Letters, v. 11, n. 6, p. 637-650, 2008.

BURNHAM, K. P.; ANDERSON, D. R. Model selection and multimodel inference: a practical information-theoretic approach. 2 ed. New York: Springer-Verlag, 2002.

CASWELL, H. Matrix population models: construction, analysis and interpretation. 2 ed. Sunderland: Sinauer, 2001.

CLEMEN, R. T.; REILLY, T. Making hard decisions with decision tools. Mason: Cengage Learning, 2004.

COHEN, J. E. Food webs and niche space. Princeton: Princeton University Press, 1978.

DARWIN, C. On the origin of species. London: Murray, 1859.

DOBZHANSKY, T. Nothing in biology makes sense except in light of evolution. American Biology Teacher, v. 35, n. 3, p. 125-129, 1973.

ELLNER, S. P.; REES, M. Integral projection models for species with complex demography. American Naturalist, v. 167, n. 3, p. 410-428, 2006.

FISHER, R. A. The design of experiments. New York: Macmillan, 1935. 
FUTUYMA, D. Biologia evolutiva. 3 ed. Ribeirão Preto: Funpec, 1998.

GOTELLI, N. J. Ecologia. Londrina: Planta, 2007.

GOTELLI, N. J.; ELLISON, A. M. Princípios de estatística em ecologia. Porto Alegre: Artmed, 2011.

HAIRSTON, N. G. et al. Rapid evolution and the convergence of ecological and evolutionary time. Ecology Letters, v. 8, n. 10, p. 1114-1127, 2005.

HARTL, D. L.; CLARK, A. G. Princípios de genética de populações. 4 ed. Porto Alegre: Artmed, 2010.

HILBORN, R.; MANGEL, M. The ecological detective: confronting models with data. Princeton: Princeton University Press, 1997.

HUBBELL, S. P. The unified neutral theory of biodiversity and biogeography. Princeton: Princeton University Press, 2001.

KÉRY, M. Introduction to WinBUGS for ecologists: a Bayesian approach to regression, ANOVA, mixed models, and related analysis. Amsterdam: Elsevier, 2010.

LANDE, R. Genetics and demography in biological conservation. Science, v. 241, n. 4872, p.1455-1460, 1988.

LEVIN, S. A. et al. The Princeton Guide to Ecology. Princeton: Princeton University

Press, 2009.

LEWONTIN, R. A tripla hélice: gene, organismo e ambiente. São Paulo: Companhia das Letras, 2002.

MADDISON, W. P. Gene trees in species trees. Systematic Biology, v. 46, n. 3, p. 523-536, 1997. 
MARTINS, R. P. et al. Rumos para a formação de ecólogos no Brasil. Revista Brasileira de Pós-Graduação, v. 4., n. 7, p. 25-41, 2007.

MAYNARD SMITH, J. Evolution and the theory of games. Cambridge: Cambridge University Press, 1982.

OKUBO, A. Diffusion and ecological problems: mathematical models. New York: Springer-Verlag, 1980.

PLATT, J. R. Strong inference - certain systematic methods of scientific thinking may produce much more rapid progress than others. Science, v. 146, n. 3642, p. 347-353, 1964.

PRAGER, S. D.; REINERS, W. A. Historical and emerging practices in ecological topology. Ecological Complexity, v. 6, n. 2, p. 160-171, 2009.

RICKLEFS, R. E. A comprehensive framework for global patterns in biodiversity. Ecology Letters, v. 7, n. 1, p. 1-15, 2004.

ROCHA, P. L. B. et al. Pós-graduação em Ecologia no Instituto de Biologia da UFBA: um currículo em evolução. Revista Brasileira de PósGraduação, v. 4, n. 8, p. 227-244, 2008.

ROSS, S. M. Introduction to probability models. 10 ed. Amsterdam: Elsevier, 2007.

ROYLE, J. A.; DORAZIO, R. M. Hierarchical modeling and inference in ecology: the analysis of data from populations, metapopulations and communities. Amsterdam:

Elsevier, 2008.

SCARANO, F. R. A expansão e as perspectivas da pós-graduação em Ecologia no Brasil. Revista Brasileira de Pós-Graduação, v. 5, n. 9, p. 89-102, 2008.

TURCHIN, P. Does population ecology have general laws? Oikos, v. 94, n. 1, p. 17-26, 2001. 
WAKELEY, J. Coalescent theory: an introduction. Greenwood Village: Roberts \& Company Publishers, 2008.

WALTERS, C. J. Adaptive management of renewable resources. Caldwell: Blackburn Press, 2001. 